\title{
PERSONAL-PSYCHO CHARACTERISTICS AND ATTITUDE TOWARDS SUICIDAL BEHAVIOUR AMONG UNIVERSITY STUDENTS IN SOUTH EASTERN STATES OF NIGERIA
}

\author{
Nyorere, Ogho Ifeanyi (Ph.D) ${ }^{1}$, James, Idopise Okon² \& Udom, Inwang Etim ${ }^{3}$ \\ Department of Educational Foundations, Guidance and Counseling, \\ University of Uyo \\ 1. inyorere@yahoo.com (08034140112, 08150760792) \\ 2idopisejames2@gmail.com (08080310181 \\ 3inwangudom@gmail.com $(08022617498)$
}

\begin{abstract}
The study aimed at determining the relationship between personal-psycho characteristics and attitude towards suicidal behaviour among University students in South Eastern States of Nigeria. Two purposes of the study, two research questions and hypotheses guided the study. The cross-sectional survey research design was used. The population of the study comprised all the 34,169 year three students in the Nine (9) government-owned and state Universities in South Eastern States of Nigeria. A sample size of 380 year three students was selected using multi-stage sampling procedure. Proportionate sampling technique was used in selecting the faculties and departments for the study. A self-structured questionnaire entitled "Personal-Psycho Characteristics and Attitude towards Suicidal Behaviour Questionnaire (PCASBQ)" was used for data collection. Data were collated and analyzed using Pearson Product Moment Collection statistics, at .05 level of significance and at 378 degree of freedom. Findings of the study showed a very high positive and significant relationship between selfesteem, depression and attitude towards suicidal behaviour among university students. Conclusion was drawn from the findings and the study recommended among other things that, University counsellors should always counsel the students about upholding self-worth, maintaining confidence and positive view of themselves in their academic and social life pursuits. This will deter the students from committing suicide when confronted with strenuous conditions.
\end{abstract}

KEYWORD: suicide, suicidal behaviour, depression and self-esteem

\section{INTRODUCTION}

Suicidal behaviour is one of the current social problems affecting the overall psycho-social wellbeing of students in public universities. It is one of the foremost social and public health problems which has currently become the third leading cause of deaths for youths between the ages of 15 and 30 years after HIV/Aids and tuberculosis. It is estimated that 800,000 people die by suicide every year representing an annual age standardized suicide rate of 11.4 per 100,000 populations globally and 6.11 per 100,000 populations in developing countries including Nigeria (WHO, 2013).

Suicidal behaviour is the act of killing oneself deliberately initiated and performed by the person concerned in the full knowledge or expectation of its results (Alabi, Alabi, Ayinde and Abdulmalik, 2015). Suicidal behaviour take different forms such as taking a drug overdose, deliberately crashing a car, dieing by hanging among others. It often response to a situation that 
Vol.8, Issue 3, pp.16-26, March 2020

Published by ECRTD- UK

Print ISSN: ISSN 2054-6351

Online ISSN: ISSN 2054-636X

overwhelms an individual such as social isolation, death of a loved one, emotional trauma, depression break in relationship, serious illness, aging, unemployment or financial problems feelings of guilt, drug dependence among other (Hudgens, 2003). Suicidal behaviour can be described as fatal and non-fatal suicidal behaviour. Fatal suicidal behaviour refers to completed suicidal behaviour that reflects the person's intention to die and where the person has managed to achieve the pre-determined goal. On the contrary, non-fatal suicidal behaviour is one that does not end the person's life and embodies several manifestations such as those seen in the attempted suicidal (Palmer, 2008).

In the days of yore, committing suicide was seen as a taboo, disgraceful and families of people who commit suicide were highly ashamed of themselves. When information is sought about an individual who has committed suicide in a family, family members will often deny that the reason for death was suicide. In many Nigerian cultures, Ugwuoke (2016) stated that rituals were performed to prevent the spirit of the person that committed suicide from disturbing living relations. Some families keep silent about family members who have committed suicide because they may sometimes not want to partake in such rituals that expose their family member as having committed suicide. Many Nigeria cultures do this as a result of the belief system that man is not the author of this life. As noted by Alabi, Alabi, Ayinde and Abdulmalik (2015), many families in the past show outright rejection to suicide because of its unexplored psychological burden of feelings of guilt, sorrow and anguish, which is often experienced by the family members and associates of the victims who commit suicide. The authors added that families, friends or acquaintances of people who attempt or commit suicide may feel shock, became angered and experience social isolation.

However, in this present dispensation particularly among public Nigerian universities, suicide has continuously become a serious public health and national problem. This is evident in the rate of suicide cases found among universities students in Nigeria. Ogunseye (2013) found that suicide cases have increased over the ten year period spanning 2009-2018, and that the average crude suicide attempt rate was 10-25 per 100,000. The author added that teenagers are the worst hit by suicide behaviour Chatterjee and Basu (2010) found that suicidal behaviours and their risk factors occur in the same prevalence and frequency for developed and developing countries. Although Nigeria experience paucity of information about the epidemiology of suicide among university students, Nwosu and Odesanmi (2001) found that majority of Nigerian youths including university students committed suicide by the ingestion of Gammalin 20 and use of the locally made gun. Similarly, Offiah and Obiorah (2014) found a total of 11 (47.83\%) hanging deaths occurring within the age group of 21-30 years of which the students are not exempted.

\section{THEORETICAL AND CONCEPTUAL REVIEW}

\section{Durkheim's Theory of Social Integration and Social regulation (1951)}

The philosophical foundation upon which prevalence of suicidal behaviour among undergraduates of universities in South Eastern State of Nigeria is built on the sociological and psychological theory of social integration and social regulation enunciated by Durkheim (1951). The theory states that there is an inverse relationship between suicidal behaviour and the degree of integration an individual has with his or her social group. The theorist proposed that suicide results, in part, from failure of social integration. The theorist posits that an individual will not 
Vol.8, Issue 3, pp.16-26, March 2020

Published by ECRTD- UK

Print ISSN: ISSN 2054-6351

Online ISSN: ISSN 2054-636X

die by suicide unless he/she has both the desire to die by suicide and the ability to do so. The theorist further described social integration as the degree to which individuals in the society were bound by social ties and relationship, while social regulation referred to the degrees to which individuals have their desires and emotions controlled by the social values of the society.

Durkheim held the view that suicidal behaviour would be more likely if social integration was too strong (leading to egoistic suicidal behaviour), if social regulation was too weak (leading to anomic suicidal behaviour), or if these two social forces were too strong (leading to altruistic and fatalistic suicidal behaviour respectively. This theory stresses that individuals who die by suicide often experience social isolation and social withdrawal before their death. Therefore, this theory is related to this work in that it shows the link between self-esteem and attitude towards suicidal behaviour among students. It is understood from this theory that students who evaluate themselves as being insignificant, isolated and unrecognized by significant others in the society (lower self-esteem) would likely feel withdrawn and increases the possibility of committing suicide. This means that the potential for suicidal behaviour increases when an individual experience some imbalance or upset with respect to his relationship with people in the social structure.

\section{The Concept of Suicidal Behaviour}

Suicide behaviour is conceptualized differently by various scholars and authors. According Alabi, et al. (2015), suicide behaviour is the act of killing oneself, deliberately initiated and performed by the person concerned in the full knowledge or expectation of its total outcome. Kerkhof (2004) defined suicidal behaviour as a deliberate act intended to end one's life in order to escape unbearable suffering or to help change adverse conditions of living. It is the intentional act of taking one's own life or the destruction of one's own interest or prospects. Maris (2002) also viewed suicidal behaviour as any willful act which is designed to end one's own life. For many, according to him, it is a crime against oneself, nature, humanity and God.

As observed by Schlebusch (2005), suicidal behaviour is the domain of thoughts, images and ideas about committing suicide or a desire to terminate one' life without the suicidal act. The author further noted that suicidal behaviour is a continuum of behaviours, ranging from a person wishing him or herself dead to the actual deed of killing themselves. According to Animasahun and Animasahun (2016), suicidal behaviour refers to complex and multi-factorial events with different behavioural characteristics incorporating a range of self-harming acts precipitated by emotional discomfort and distress. Rick factors such as psychological distress, exposure to bullying and violence, parental involvement, and alcohol and illicit drug abuse have been associated with significant increase in the risk for youth suicidal behaviour (Randall, Doku, Wilson and Peltzer, 2014). Therefore, it could be deduced from the definitions that suicidal behaviour is an intentional death, a self-inflicted death which one makes an intentional direct and conscious effort towards putting an end to life.

\section{Self-Esteem and Students Attitude towards Suicidal Behaviour}

Self-esteem refers to the evaluations individuals make about themselves, and is shaped by individual's appraisals of how they are perceived by significant other (Sullivan, 2003). The quality of feedback received by others from the environment significantly affects ones functioning and ability to cope with strenuous conditions that may lead to suicide. During 
Vol.8, Issue 3, pp.16-26, March 2020

Published by ECRTD- UK

Print ISSN: ISSN 2054-6351

Online ISSN: ISSN 2054-636X

depressive condition, an individual may develop lower self esteem which may adversely lead to suicidal ideation. Tarriar (2008) found that lower self-esteem one of the is a major reasons for suicidal behaviour among students. Garber, Robinson and Valentiner (2007) found that a negative self-esteem predisposes adolescents to depression and other psychiatric difficulty which could lead to committing suicide.

Students who evaluate themselves as not having the capacity to succeed or perform well academically may be involved in suicide. Such negative self-esteem predisposes some students to commit suicide over academic performance. For instance, Kolapo Olowoporoku, a student of Obafemi Awolowo University Ile-Ife was reported committing suicide after repeatedly failing some courses. The victim, as noted by Alfred (2019), was an extra year computer science student who swallowed a poisonous substance which led to is death.

Also, feeling of inferiority complex is another aspect of lower self-esteem which could make a student resort to committing suicide. Godwin and Marusie (2003) found in one of their study that feelings of inferiority were associated with a significant increased likelihood of suicidal ideation and suicidal attempt. In other words, students with low self-esteem are confused with imaginings of what others think about him; hence, bringing about feelings of loneliness, helplessness, and fearfulness. They typically experience difficulties in establishing and maintaining meaningful personal relationship.

Studies have shown a link between self-esteem and attitude towards suicidal behaviour among students. One of the study for conducted by Vega, Gil, Zimmerman and Warheit (2003), the authors found that female students who manifested lower self-esteem are likely to commit suicidal behaviour in public schools than those with high self-esteem. Also, Reynolds and Mazza (2004) assessed suicidal behaviour in a sample of 2412 high school students, the author found the highest rate of history of suicidal attempts among students, which was as a result of low self-esteem. Kerkhof (2004) also revealed that suicidal behaviour was more prevalent among young men and women with lower self-esteem, emotional and relationship problems.

\section{Depression and Students Attitude towards Suicidal Behaviour}

Depression is a state of feeling very unhappy, sad, and worthless; and an intense lost of interest in crucial life activities. It can lead to a variety of emotional and physical problems which can decrease a person's ability to function at work or at home. Depression is a common serious medical illness that negatively may affects how an individual feel, thinks and function in daily activities. It causes feelings of sadness or a lost of interest in activities which an individual enjoyed. Feeling downcast sometimes is a normal part of life, but when emotions such as hopelessness and despair take hold, depression is likely to occur. According to Elgard and Arlett, (2002), depression changes vary from person to person with common signs and symptoms. Some of the symptoms include feelings of helplessness and hopelessness, loss of interest in daily activities, appetite or weight changes, sleep changes, loss of energy, selfloathing (strong feelings of worthlessness or guilt), concentration problems and unexplained aches and pains. Hopelessness, as observed by Schaier and Carller (2005), is a major symptom of depression and is a cluster of negative expectancies concerning a person and his or her future. Hopelessness is associated with increased incidence of hypertension, feelings of isolation, psychological morbidity which may lead to committing suicide. 
Ugwuoke (2016) stated that depression is characterized by a feeling of sadness and hopelessness, which could arise from lack of social support, poverty, drug abuse, physical illness among others. The author ascribed the above causes of suicide among students to emergence of depression. This shows that suicidal attempts increase with the increasing severity of depression. Empirical studies have shown the link between depression and suicidal actions of students in higher institutions. One of such studies was conducted by Okoedion and Okolie (2019) on youth suicidal behaviour: an evaluation of risk factors in Edo State, Nigeria. The authors sees suicide as one of the most serious social and public health problems in Nigeria; and also found depression to be a major risk factor predicting suicidal behaviour among youths. Also, Wanyoike (2015) also conducted similar study on suicide among university students in Kenya: causes, implications and interventions. One of the major findings of the study showed that depression is a risk factor leading to suicidal attempts, creating dangerous impact on the family and society.

\section{Statement of the Problem}

Suicide has become one of the leading causes of death especially in the 15-30years old age group all over the world. The individuals who commit suicide have a motivation to put an end to their depressive conditions. This seems to be very common among university students who are always confronted with unsatisfactory condition that put those affected at risk for attempted suicide or suicide. In most cases, young's ones are not free to discuss their feelings or problems with adults. The harboured feelings and experiences stored in the mind may result in intense depression and suicide. If depression are not nipped in the bud in students, the rate of suicide may become so alarming, which would be detrimental to national wellbeing.

Also, lower self esteem as observed by the research sometimes induces students into committing suicide. This may occur if a child always sees himself or herself as being so inferior or worthless over others and being unable to cope with learning disabilities, poor financial status, broken homes academic stress among others. For instance, on Monday May $20^{\text {th }}, 2019$, Chukwuemeka Akachi, a 400-level student of the Department of English and Literacy Studies, University of Nigeria, Nsukka (UNN) was reported committing suicide after taking two bottles of an Insecticide Sniper (Muanya,2019). Also, Fidelis, Huruna and Umar (2019) stated that in no fewer than 42 Nigerians, 11 students among them committed suicide within the first and second quarters of the year; and that majority of the victims ended their lives by consuming the deadly insecticide called sniper while others either drank acid. In explaining reasons why Nigerian youths are committing suicide, Onyedika (2019) noted academic failure to be one of the major reasons. The author cited a case of a 300 level student of medicine and surgery, at the Faculty of Basic Medical of the Niger Delta University (NDU) Ammasoma, who committed suicide after realizing that he was among the 22 students short-listed to be withdrawn from the college for failing the Bachelor of Medicine Examination. This situation seems to be on the increase in recent times and makes this study apt.

\section{Purpose of the Study}

The main purpose of the study was to determine the relationship between personal psycho characteristics and attitude towards suicidal behaviour among university students in South Eastern States of Nigeria. Specifically, the study sought to determine: 
1. The relationship between self-esteem and attitude towards suicidal behaviour among university students in South Eastern States of Nigeria.

2. The relationship between depression and attitude towards suicidal behaviour among university students in South Eastern States of Nigeria.

\section{Research Questions}

The following research questions were guided the study:

1. What is the relationship between self-esteem and attitude towards suicidal behaviour among university students in South Eastern States of Nigeria?

2. What is the relationship between depression and attitude towards suicidal behaviour among university students in South Eastern States of Nigeria?

\section{Research Hypotheses}

The following research hypotheses were guided the study:

1. There is no significant relationship between self-esteem and attitude towards suicidal behaviour among university students in South Eastern States of Nigeria.

2. There is no significant relationship between depression and attitude towards suicidal behaviour among university students in South Eastern States of Nigeria.

\section{Design of the Study}

The cross-sectional survey research design was used. Uzoagulu (1998) asserted that the crosssectional survey research design is considered one of the best available designs for purpose of describing a population that is fairly large. This design permits the description of conditions as they exist in their natural settings. The present study involves a large population and the conditions of the data or responses were described as they existed in their natural settings; hence, the design is suitable for this study as it helped in determining the relationship between personal-psycho characteristics and attitude towards suicidal behaviour among university students in South Eastern States of Nigeria

\section{Population of the Study}

The population of the study comprised all the 34,169 year three students in the Nine (9) government-owned and state Universities that make up South Eastern States of Nigeria. This universities are Abia State University, Uturu; Michael Okpara University of Agriculture, Umudike; Anambra State University of Technology, Uli; Nnamdi Azikiwe University Awka; Ebonyi State University, Abakaliki; Enugu State University of Technology, Enugu; University of Nigeria, Nsukka and Imo State University, Owerri (National University Commission, Abuja, 2019).

\section{Sample and Sampling Technique}

A sample size of 380 year three students was selected using multi-stage sampling procedure. In the first stage, this sample size was determined statistically using Kierje and Morgan (1975) sampling procedure, which state that any population that ranges from 30,000 to 40,000 , a sample of 380 was representative of the population. The second stage involved the used of systematic random sampling technique in selecting 4 public and state universities for the study. A systematic random sampling technique is one in which every second, third, fifth or tenth number is chosen from a list of or array of the populace (Udoh and Joseph, 2005). Hence, the 
Universities were arranged numerically from 1-9; thereafter, every even-numbered Universities were selected for the study. The third stage involved the use of proportionate sampling technique in selecting the faculties and departments for the study. The respondents were duly selected from each of the departments using hat and draw method of random sampling.

\section{Instrumentation}

A self-structured questionnaire entitled "Personal-Psycho Characteristics and Attitude towards Suicidal Behaviour Questionnaire (PCASBQ)" was used for data collection. The items were framed in line with the research questions and hypotheses. The instrument had two parts. Section (A) contained 10 items on psycho-personal characteristics while section (B) contained 8 items measuring attitude towards suicidal behaviour. The PCASBQ was scored using a four point rating scale of:

Strongly Agree $(\mathrm{SA})=4$

Agree $(\mathrm{A})=3$

Disagree $=2$

Strongly Disagree $(\mathrm{SD})=1$

The respondents were required to tick $(\sqrt{ })$ from a list of options as individuals.

\section{Validation of the Instrument}

To ensure the face validity of the instrument, three copies of the instrument were given to three experts. One of the experts was a lecturer from the Sociology of Education Unit while the other two were lecturers from Measurement and Evaluation Unit of Department of Educational Foundation, Guidance and Counselling, University of Uyo, Nigeria. The purpose for giving them the instrument was to assess the suitability or otherwise of the items in the instrument. The inputs and corrections made by the evaluators and that of the researchers' supervisor were used to form the final copy for administration.

\section{Reliability of the Instrument}

To ascertain the reliability index of the instrument, Cronbach Alpha reliability method was adopted. The researcher pilot-tested the instrument on 40 University students who were not part of the sample but were part of the study area. Data generated from the trial test were analysed using Cronbach Alpah Reliability Analysis. The overall Cronbach's Alpha coefficient obtained was 0.79 for items in section A and 0.83 for items in section B. This instrument was considered reasonable for the current research work because according Nunnally (2007), any instrument that has the reliability co-efficient of 0.50 and above should be accepted.

\section{Method of Data Collection}

The research instruments were personally administered on the respondents in their respective departments by the researcher together with four trained research assistants.

\section{Method of Data Analysis}

Data generated was analysed using Pearson Product Moment Correlation (PPMC) for answering the research questions. In answering the research questions, the r-value was used to determine the weight or extent of relationship between variables. The same statistical tool (PPMC) was used for testing of hypotheses by comparing the r-value with the critical value, so as to 
Vol.8, Issue 3, pp.16-26, March 2020

Published by ECRTD- UK

Print ISSN: ISSN 2054-6351

Online ISSN: ISSN 2054-636X

determine the significant of the relationship between variables all at .05 level of significance and at 378 degree of freedom.

The research questions were answered using the decision rule for answering questions in a correlational study, as presented by Uzoagulu's (2011) as follows:-

Coefficient (r) - Relationship

\pm .00 to $\pm .20 \quad$ - $\quad$ Negligible, weak, very low, little or none

\pm .21 to $\pm .40 \quad$ - $\quad$ Present, slight, but low

\pm .41 to $\pm .60 \quad$ - $\quad$ Average, moderately high, fairly high

\pm .61 to $\pm .1 .00 \quad-\quad$ Very high

For the null hypotheses, the standard for decision was to reject the null hypotheses when the calculated r-value is greater than or equals to the critical value, and retained when the calculated value is less than the critical value.

\section{RESULTS AND DISCUSSION OF FINDINGS}

\section{Research Question One}

What is the relationship between self-esteem and attitude towards suicidal behaviour among university students in South Eastern States of Nigeria?

\section{Hypothesis One}

There is no significant relationship between self-esteem and attitude towards suicidal behaviour among university students in South Eastern States of Nigeria.

This hypothesis was formulated to determine the relationship between self-esteem and attitude towards suicidal behaviour among university students. To determine this relationship, the Pearson Product-Moment Correlation (PPMC) statistics was used in analyzing the data. The result is as shown in Table 1.

Table 1: Summary of analysis of relationship between self-esteem and attitude towards suicidal behaviour among university students

\begin{tabular}{llllll}
\hline Variables & $\mathrm{N}$ & $\sum \mathrm{x}$ & $\sum \mathrm{x}^{2}$ & $\sum \mathrm{xy}$ & $\mathrm{r}$-cal \\
\hline Self-Esteem (x) & 380 & 4849 & 71156 & 155987 & .72 \\
$\begin{array}{l}\text { Students Attitude } \\
\text { towards Suicidal }\end{array}$ & & & & \\
$\begin{array}{l}\text { Behaviour (y) } \\
\text { 3eho }\end{array}$ & 8304 & 346022 & & \\
\hline
\end{tabular}

$\mathrm{P}<.05 ; \mathrm{df}=378 ;$ crit. $\mathrm{r}=1946$

From Table 1, in answering the research question, it can be said that self-esteem has very high positive but significant relationship with attitude towards suicidal behaviour of University students in South Eastern Nigeria. This is evidence on the correlation coefficient of .72. In testing the hypothesis, it is seen that the calculated r-value is greater than the critical r-value of .1946 when compared at .05 confidence level with 378 degrees of freedom. Based on this finding the null hypothesis was rejected as the correlation coefficient was significant. The 
Vol.8, Issue 3, pp.16-26, March 2020

Published by ECRTD- UK

Print ISSN: ISSN 2054-6351

Online ISSN: ISSN 2054-636X

finding suggests that students' attitude towards suicidal behaviour is significantly related to their level of self-esteem.

\section{Research Question Two}

What is the relationship between depression and attitude towards suicidal behaviour among university students in South Eastern States of Nigeria?

\section{Hypothesis Two}

There is no significant relationship between depression and attitude towards suicidal behaviour among university students in South Eastern States of Nigeria.This hypothesis was formulated to determine the relationship between depression and attitude towards suicidal behaviour among university students. To determine this relationship, the Pearson Product-Moment Correlation (PPMC) statistics was used in analyzing the data. The result is as shown in Table 2.

Table 2: Summary of analysis of relationship between depression and attitude towards suicidal behaviour among university students

\begin{tabular}{lccccc}
\hline Variables & $\mathrm{N}$ & $\sum \mathrm{x}$ & $\sum \mathrm{x}^{2}$ & $\sum \mathrm{xy}$ & $\mathrm{r}$-cal \\
\hline Depression (x) & 380 & 3533 & 62939 & 146632 & .86 \\
& & & & & \\
$\begin{array}{l}\text { Students Attitude towards } \\
\text { Suicidal Behaviour (y) }\end{array}$ & 380 & 8304 & 346022 & & \\
\hline
\end{tabular}

$\mathrm{P}<.05 ; \mathrm{df}=298 ;$ crit. $\mathrm{r}=1946$

From Table 2, in answering the research question, it can be said that depression has very high positive but significant relationship with attitude towards suicidal behaviour University students in South Eastern Nigeria. This is evidence on the correlation coefficient of .86. In testing the hypothesis, it is seen that the calculated r-value is greater than the critical r-value of .1946 when compared at .05 confidence level with 378 degrees of freedom. Based on this finding the null hypothesis was rejected as the correlation coefficient was significant. The finding suggests that students' attitude towards suicidal behaviour is significantly related to their level of depressive thoughts; and intense feelings of sadness and hopelessness.

\section{DISCUSSION OF FINDINGS}

The researchers made a combined discussion of findings from the research questions and hypotheses of the study.

\section{Self-Esteem and Attitude towards Suicidal Behaviour among Students}

Results from research question one and hypothesis one showed that self-esteem has very high positive and significant relationship with attitude towards suicidal behaviour among university students in South Eastern Nigeria. This finding is in line with the finding of the study conducted by Vega, Gil, Zimmerman and Warheit (2003). The authors found that female students who acquired lower self-esteem are likely to commit suicidal behaviour in public schools than those with high self-esteem. This finding is also in agreement with the finding of the study conducted 
Vol.8, Issue 3, pp.16-26, March 2020

Published by ECRTD- UK

Print ISSN: ISSN 2054-6351

Online ISSN: ISSN 2054-636X

by Reynolds and Mazza (2004). The authors found that the highest rate of suicidal attempts among students was as a result of lower self-esteem. Kerkhof (2004) also revealed that suicidal behaviour was more prevalent among young men and women with lower self-esteem, emotional and relationship problems. This means that the attitude of students toward suicidal behaviour is highly determined by their level of self-esteem.

\section{Depression and Attitude towards Suicidal Behaviour among Students}

Results from research question two and hypothesis two showed that depression has very high positive and significant relationship with attitude towards suicidal behaviour among university students in South Eastern Nigeria. This finding is in line with the finding of the study conducted by Okoedion and Okolie (2019). The authors sees suicide as one of the most serious social and public health problems in Nigeria; and also found depression to be a major risk factor predicting suicidal behaviour among youths. This finding is also in tandem with the findings of the study conducted by Wanyoike (2015), who found that depression is a risk factor leading to suicidal attempts, creating dangerous impact on the family and society. From the above finding, it is therefore observed that depressive thoughts, intense feelings of sadness and hopelessness may motivate students into committing suicide.

\section{CONCLUSION}

Student suicidal behaviour is seen as the most serious and public health problem affecting the Nigerian society. It is stated in this work that suicidal behaviour among university students as created dangerous impacts on the family and society at large. From the finding of this study, it is therefore concluded that among other factors predisposing students to suicide, lower self-esteem and depression are strong psycho-personal variables encouraging suicidal behaviour among students.

\section{Recommendations}

The following recommendations have been made based on the findings and discussions.

1. University counsellors should always counsel the students about upholding self-worth, maintaining confidence and positive view of themselves in their academic and social life pursuits. This will deter the students from committing suicide when confronted with strenuous conditions.

2. Programmes on how to develop positive mental health attitudes by the depressed students should always be planned and promoted by the university authorities in order to ensure the balanced and holistic development of the young ones.

\section{References}

Alabi, O., Alabi, A., Ayinde, O. and Abdulmalik, J. (2015). Suicide and suicide behaviours in Nigeria: A review. Medical Students Association Journal of University of Ibadan, 20(2): $1-5$

Alfred, O. (December 5, 2019). Student commits suicide over academic performance. Premium Times, 5-6p. 
Vol.8, Issue 3, pp.16-26, March 2020

Published by ECRTD- UK

Print ISSN: ISSN 2054-6351

Online ISSN: ISSN 2054-636X

Chatterjee, I. and Basu, J. (2010). Perceived causes of suicide, reasons for living and suicidal ideation among students. Journal of the Indian Academy of Applied Psychology, 36(2): 311-316.

Durkheim, E. (1951). Suicide. New York: Free Press.

Fidelis, M., Haruna, I. and Umar, S. (2019, June 23). Students top list as 42 Nigerians commit suicide in 6 months. The Daily Trust, 32: 8 yy-10).

Hudgens, R. (2003). Preventing suicides. New England Journal of Medicine, 308, 97-98.

Kerkhof, A. (2004). Suicide and attempted suicide. World Health, 49(2): 18-20

Maris, R. (2002). How are suicides different? In: Ronald W., Alan L., John, T and Robert, I (Eds.), Assessment and Prediction of suicide. New York: Guildford Press.

Muanya, C. (December 2, 2019). Nigeria: addressing rising cases of suicide among teachers. The guardian Newspaper, 5-6p.

Nunally, J. (2007). Psychometric theory. New York: Mc-Graw-Hill.

Nwosu, S. and Odesanmi, W. (2001). Pattern of suicides in Ile-Ife, Nigeria. West African Journal of Medicine, 20(3): 259-262.

Offiah, S. and Obiorah, C. (2014). Patern of suicide in Nigeria: The Nigeria Delta experience. Journal of Medical Investigations and Practice, 9(1) 8-11.

Ogunseye, T.(2013). Why more Nigerians are committing suicide. http://www.nairaland.com 720792/why-more-n. (Retrieved December 10, 2019).

Oyedika, A. (2019, May 25). Reasons why Nigerian youth are committing suicide. http://www.health.harvard.edu. (Retrieved December 12, 2019)

Palmier, J. (2008). Prevalence and correlates of suicidal ideation among students in subSaharan Africa. Masters Thesis in Public Health, Georgia State University.

Randall, J., Doku, D. Wilson, M .and Peltzer, K. (2014). Suicidal behaviour and relatedrisk factors among school-aged youth in the republic of Benin. PLOS ONE, 9(2): 1-9.

Reynolds, W. and Mazza, J. (2004). Suicide and suicidal behaviours in children and adolescents. In: W. M. Reynolds and H.J. Johnson (Eds), Handbook of depression in children and adolescents. New York: Plenum.

Schlebusch, L. (2005). Suicidal behaviour in South Africa. Scotssville, South Africa: University of Kwazulu-Natal Press.

Udoh, A. and Joseph, E. (2005). Foundations of Educational Research. Ikot Ekpene: Joe Graph Publications.

Ugwuoke, A. (2016). Precipitants of suicide among secondary school students in Nigeria. Bassery Andah Journal, 9(2): 147-156.

Uzoagulu, A. (1998). Practical guide to writing research project reports in tertiary institutions. Enugu: John Jacob's Classic Publishers Ltd.

Uzoagulu, A.. (2011). Practical guide to writing. Research project reports in tertiary institutions. Enugu: Cheaston Limited.

Wanyoike, B. (2015). Suicide among university students in Kenya: Causes, implications and interventions. Journal of Language, Technology and Entrepreneurship in African, 6(1): 35-53.

World Health Organization (WHO, 2013). Suicide rate increasing. http://newswise.com/.articles/view/545457 (Retrieved December 8, 2019). 